\title{
Diagnostic challenges and pitfalls of myelin oligodendrocyte glycoprotein antibody-associated demyelination
}

\author{
Lessons from neuropathology
}

Romana Höftberger, MD, and Ellen Gelpi, MD, EFN, PhD

Neurol Neuroimmunol Neuroinflamm 2019;6:e544. doi:10.1212/NXI.0000000000000544

Antibodies against myelin oligodendrocyte glycoprotein (MOG) are associated with a wide spectrum of demyelinating CNS diseases such as clinically isolated syndrome (CIS), neuromyelitis optica spectrum disorder (NMOSD), optic neuritis (ON), myelitis, acute demyelinating encephalomyelitis (ADEM), or multiphasic demyelinating encephalomyelitis (MDEM). ${ }^{1}$ Several brain biopsy-based cases of MOG antibody-associated demyelination have been described so far and have reported perivascular (ADEM) or confluent (CIS, MS, NMOSD) demyelination with relative preservation of axons, numerous macrophages, and well-preserved astrocytes. The inflammatory infiltrates have been mostly described as perivascular and parenchymal $\mathrm{T}$ cells along with some perivascular B cells. Moreover, actively demyelinating lesions may also show terminal complement complex (C9neo) deposition and can display relatively well-preserved, partly MOGnegative preoligodendrocytes. ${ }^{2-4}$

The article by Patterson et al. published in this issue of Neurology ${ }^{\circledR}$ Neuroimmunology \& Neuroinflammation addresses the challenges and potential pitfalls in the differential diagnostic work-up of brain biopsies in patients with MOG-spectrum disorders. The authors described 2 patients, 1 child and 1 adult, who clinically presented with meningoencephalitis, and brain biopsy revealed predominantly perivascular lymphocytic infiltrates involving the vessel wall, which led to the (mis)diagnosis of small-vessel vasculitis. Both patients were retrospectively tested positive for MOG antibodies and the diagnosis was changed into anti-MOG encephalitis. ${ }^{5}$ The treatment of the pediatric patient was subsequently changed into a B-cell depletion with good clinical and serologic response. In the second patient, the finding of MOG antibodies did not change the treatment strategy as she was already clinically stable; however, an earlier detection of MOG antibodies could have prevented the brain biopsy. ${ }^{5}$

The histopathologic diagnosis in small brain biopsies in the context of an inflammatory disease can be a major challenge, and an algorithmic approach for the neuropathologic work-up has been recommended to establish a correct diagnosis. ${ }^{6}$ Lymphocytic infiltrates within the brain parenchyma involving gray and/or white matter and around vessels may raise several differential diagnoses, including different inflammatory demyelinating diseases (e.g., ADEM, acute hemorrhagic leukoencephalitis, and X-linked adrenoleukodystrophy), autoimmune or paraneoplastic disorders, other inflammatory or infectious diseases (e.g., vasculitis, viral infections, and sarcoidosis), sentinel lesions preceding lymphomas, tumors (e.g., lymphomas and astrocytomas), and infarcts, among other rare conditions. The neuropathologic hallmark of CNS vasculitis comprises inflammatory infiltration of the vessel wall, fibrinoid necrosis, and inflammatory destruction of the vessels resulting in luminal thrombosis, ultimately causing ischemic brain lesions or hemorrhages. The vasculitis may be accompanied by mild-to-severe

From the Institute of Neurology, Medical University of Vienna, Austria.

Funding information and disclosures are provided at the end of the article. Full disclosure form information provided by the authors is available with the full text of this article at Neurology.org/NN.

This is an open access article distributed under the terms of the Creative Commons Attribution-NonCommercial-NoDerivatives License 4.0 (CC BY-NC-ND), which permits downloading and sharing the work provided it is properly cited. The work cannot be changed in any way or used commercially without permission from the journal. 
inflammatory infiltrates of the CNS parenchyma, but in contrast to ADEM or MS, demyelination is typically absent. ${ }^{6}$

In the 2 brain biopsies presented by Patterson et al., ${ }^{5}$ the retrospective analysis of the histopathology could not confirm the initial diagnosis of small-vessel CNS vasculitis. In both patients, the inflammatory infiltrates did not affect the vessel walls, and fibrinoid necrosis, hemorrhage, or ischemia was absent. In the first (pediatric) case, the inflammation was accompanied by a small rim of perivascular demyelination, fulfilling the neuropathologic criteria of ADEM. At the time of biopsy, the brain MRI showed T2 abnormalities in the basal ganglia, cerebellar peduncles, and supratentorial white matter. Several months after disease onset, the child developed an episode of $\mathrm{ON}$ and 2 years later, another relapse with extensive white matter abnormalities. Children with ADEM and MOG antibodies are at risk of developing clinical relapses, often with $\mathrm{ON}$, subsequently leading to a diagnosis of ADEM associated with recurrent ON (ADEMON), MDEM, or NMOSD. ${ }^{1}$ The MRI of the second (adult) patient showed unilateral hyperintense gyriform fluid-attenuated inversion recovery (FLAIR) signal abnormalities over the left temporal, parietal, and occipital lobes. The brain biopsy revealed perivascular inflammatory infiltrates, but no clear evidence of demyelination. ${ }^{5}$ Unilateral cortical lesions depicted in FLAIR images were previously described in adult patients with steroidresponsive encephalitis associated with MOG antibodies. ${ }^{7}$ Subsequently, this syndrome has been included in the spectrum of MOG antibody-associated diseases; however, neuropathologic descriptions were lacking so far. The current case may add this information to the existing literature. The absence of demyelination described by Patterson et al. may result from a sampling error of the small brain biopsy; alternatively, it may reflect the far end of a spectrum of MOG antibody-associated diseases with only minor or even absent demyelination. From experimental autoimmune encephalitis models, we learned that the extent of demyelination in MOG-induced autoimmunity seems to depend on the balance between the levels of encephalitogenic $\mathrm{T}$ cells and demyelinating MOG antibodies. Although an excess of $\mathrm{T}$ cells occurred with inflammatory infiltrates in meninges and perivascular spaces, an excess of MOG antibodies was found associated with confluent demyelinating lesions. ${ }^{8}$ Accordingly, intensive perivascular inflammation but sparse or even absent demyelination in human MOG-spectrum diseases may, among other factors (e.g., genetic, infectious), reflect a scenario, where an encephalitogenic $\mathrm{T}$-cell response dominates over a demyelinating antibody response (with variable antibody titer, affinity) against conformational MOG epitopes.

The 2 patients described by Patterson et al., and other reports of patients diagnosed with CNS small-vessel vasculitis by brain biopsy, who later developed $\mathrm{ON}$ or myelitis ${ }^{7}$ raise the possibility that misdirecting diagnoses may not be unusual because biopsy specimens are frequently small and often represent only part of the entire pathologic process. Small CNS biopsies with inflammation should be thoroughly analyzed for demyelination, extent, and localization of inflammation (perivascular vs parenchymal), and axonal damage. Additional immunohistochemical stainings for $\mathrm{T}$ and $\mathrm{B}$ cells, plasma cells, astrocytes, and macrophages may narrow the differential diagnosis. Neuropathology requires a multidisciplinary approach, and the findings should be assessed together with neurologic and neuroradiologic data. The current study emphasizes that in some cases, testing for autoantibodies in serum and CSF provides useful additional information for the proper clinicopathologic classification of a disease.

\section{Study funding}

No targeted funding reported.

\section{Disclosure}

The Medical University of Vienna receives payments for antibody assays (MOG, AQP4, and other autoantibodies). Dr. Höftberger received speakers' honoraria from Euroimmun and research support from the Jubiläumsfonds der Österreichischer Nationalbank, Project 16919, and the Austrian Science Fund (FWF):I3334-B27; E. Gelpi served on the scientific advisory board of Institut du Cerveau et de la Moelle epiniere, served as an editorial board member of Neuropathology and Applied Neurobiology, served as an associate editor of Clinical Neuropathology, received research support from Fundacion Tatiana Perez de Guzman el Bueno and Fundacio la Marato de TV3 Convocatoria Malalties Neurogeneratives. Full disclosure form information provided by the authors is available with the full text of this article at Neurology.org/NN.

\section{Publication history}

Received by Neurology: Neuroimmunology \& Neuroinflammation January 4, 2019. Accepted in final form January 9, 2019.

\section{References}

1. Reindl M, Waters P. Myelin oligodendrocyte glycoprotein antibodies in neurological disease. Nat Rev Neurol Epub 2018 Dec 17.

2. Höftberger R, Lassmann H. Inflammatory demyelinating diseases of the central nervous system. Handb Clin Neurol 2017;145:263-283.

3. Lang J, Biebl A, Gruber A, et al. Teaching case 5-2018: integrated morphological and immunological work-up of neurosurgical specimen allows accurate diagnosis of neuroinflammatory lesions: an example of acute disseminated encephalomyelitis (ADEM) associated with anti-MOG antibodies. Clin Neuropathol 2018;37:206-208.

4. Spadaro M, Gerdes LA, Mayer MC, et al. Histopathology and clinical course of MOGantibody-associated encephalomyelitis. Ann Clin Transl Neurol 2015;2:295-301.

5. Patterson K, Iglesias E, Nasrallah M, et al. Anti-MOG encephalitis mimicking small vessel CNS vasculitis. Neurol Neuroimmunol Neuroinflamm 2019;XX:XXX.

6. Kuhlmann T, Lassmann H, Brück W. Diagnosis of inflammatory demyelination in biopsy specimens: a practical approach. Acta Neuropathol 2008;115:275-287.

7. Ogawa R, Nakashima I, Takahashi T, et al. MOG antibody-positive, benign, unilateral, cerebral cortical encephalitis with epilepsy. Neurol Neuroimmunol Neuroinflamm 2017;4:e322. doi: 10.1212/NXI.0000000000000322.

8. Lassmann H, Brunner C, Bradl M, Linington C. Experimental allergic encephalomyelitis: the balance between encephalitogenic $\mathrm{T}$ lymphocytes and demyelinating antibodies determines size and structure of demyelinated lesions. Acta Neuropathol 1988;75:566-576. 


\section{Neurology \\ Neuroimmunology \& Neuroinflammation}

\section{Diagnostic challenges and pitfalls of myelin oligodendrocyte glycoprotein antibody- associated demyelination: Lessons from neuropathology \\ Romana Höftberger and Ellen Gelpi \\ Neurol Neuroimmunol Neuroinflamm 2019;6; \\ DOI 10.1212/NXI.0000000000000544}

This information is current as of February 1, 2019

Updated Information \&
Services

References

Subspecialty Collections

Permissions \& Licensing

Reprints including high resolution figures, can be found at:

http://nn.neurology.org/content/6/2/e544.full.html

This article cites 6 articles, 0 of which you can access for free at: http://nn.neurology.org/content/6/2/e544.full.html\#\#ref-list-1

This article, along with others on similar topics, appears in the following collection(s):

All Demyelinating disease (CNS)

http://nn.neurology.org//cgi/collection/all_demyelinating_disease_cns Autoimmune diseases

http://nn.neurology.org//cgi/collection/autoimmune_diseases

Vasculitis

http://nn.neurology.org//cgi/collection/vasculitis

Information about reproducing this article in parts (figures,tables) or in its entirety can be found online at:

http://nn.neurology.org/misc/about.xhtml\#permissions

Information about ordering reprints can be found online:

http://nn.neurology.org/misc/addir.xhtml\#reprintsus

Neurol Neuroimmunol Neuroinflamm is an official journal of the American Academy of Neurology.

Published since April 2014, it is an open-access, online-only, continuous publication journal. Copyright

Copyright $\odot 2019$ The Author(s). Published by Wolters Kluwer Health, Inc. on behalf of the American

Academy of Neurology.. All rights reserved. Online ISSN: 2332-7812.

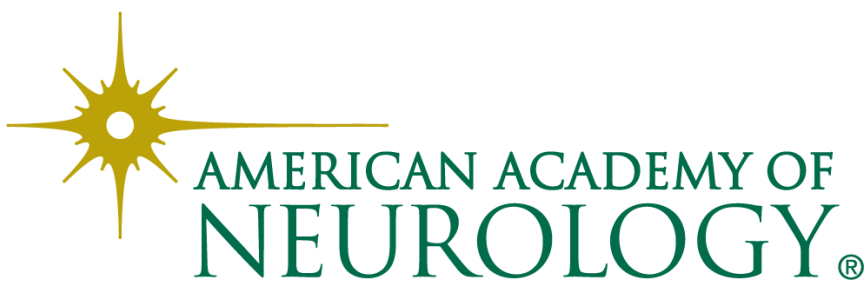

